\title{
New 11,20-Epoxybriaranes from the Gorgonian Coral Junceella fragilis (Ellisellidae)
}

Chia-Cheng Lin ${ }^{1}$, Jui-Hsin Su ${ }^{2,3}$, Wu-Fu Chen ${ }^{1,4}$, Zhi-Hong Wen ${ }^{4} \mathbb{1}$, Bo-Rong Peng ${ }^{2}$, Lin-Cyuan Huang $2,3, *$, Tsong-Long Hwang $5,6,7,8,9,10, *$ (i) and Ping-Jyun Sung $2,3,4,11,12, *$ (i)

1 Department of Neurosurgery, Kaohsiung Chang Gung Memorial Hospital and Chang Gung University College of Medicine, Kaohsiung 833, Taiwan

2 National Museum of Marine Biology and Aquarium, Pingtung 944, Taiwan

3 Graduate Institute of Marine Biology, National Dong Hwa University, Pingtung 944, Taiwan

4 Department of Marine Biotechnology and Resources, National Sun Yat-sen University, Kaohsiung 804, Taiwan

5 Research Center for Chinese Herbal Medicine, College of Human Ecology, Chang Gung University of Science and Technology, Taoyuan 333, Taiwan

6 Research Center for Food and Cosmetic Safety, College of Human Ecology, Chang Gung University of Science and Technology, Taoyuan 333, Taiwan

7 Graduate Institute of Healthy Industry Technology, College of Human Ecology, Chang Gung University of Science and Technology, Taoyuan 333, Taiwan

8 Graduate Institute of Natural Products, College of Medicine, Chang Gung University, Taoyuan 333, Taiwan

9 Chinese Herbal Medicine Research Team, Healthy Aging Research Center, Chang Gung University, Taoyuan 333, Taiwan

10 Department of Anaesthesiology, Chang Gung Memorial Hospital, Taoyuan 333, Taiwan

11 Graduate Institute of Natural Products, Kaohsiung Medical University, Kaohsiung 807, Taiwan

12 Chinese Medicine Research and Development Center, China Medical University Hospital, Taichung 404, Taiwan

* Correspondence: bigpa830123@gmail.com (L.-C.H.); htl@mail.cgu.edu.tw (T.-L.H.); pjsung@nmmba.gov.tw (P.-J.S.); Tel.: +886-8-882-5001 (ext. 1384) (L.-C.H.); +886-3-211-8800 (ext. 5523) (T.-L.H.); +886-8-882-5037 (P.-J.S.); Fax: +886-8-882-5087 (L.-C.H. \& P.-J.S.); +886-3-211-8506 (T.-L.H.)

Academic Editors: Pavel B. Drasar and Vladimir A. Khripach Received: 14 June 2019; Accepted: 5 July 2019; Published: 7 July 2019

\begin{abstract}
Two new 11,20-epoxybriaranes, fragilides P (1) and Q (2), as well as two known analogues, robustolide F (3) and juncin Z (4), were obtained from the gorgonian coral Junceella fragilis. The structures, including the absolute configurations of briaranes $\mathbf{1}$ and $\mathbf{2}$, were elucidated by using spectroscopic methods and comparing the spectroscopic and rotation data with those of known related analogues. Briarane 4 decreased the generation of superoxide anions by human neutrophils. The propionate group in $\mathbf{1}$ is rarely found.
\end{abstract}

Keywords: Junceella fragilis; fragilide; briarane; superoxide anion

\section{Introduction}

Since the first structure elucidation of a briarane-type natural product, briarein A, in 1977 by single-crystal X-ray diffraction analysis [1], over 700 marine origin briaranes have been isolated and reported from various octocorals, especially from genera Briareum (family Briareidae) [2] and Junceella (family Ellisellidae) [3-5]. Among these compounds, 11,20-epoxybriaranes were proven to be a chemical marker for the gorgonian corals belonging to family Ellisellidae [6]. During the course of our research on new natural substances from the marine invertebrates distributed in the waters of Taiwan, a series of briarane-type diterpenoids were isolated from various octocorals belonging to the 
genera Junceella [7] and Briareum [8], and the compounds of this type were proven to possess various interesting bioactivities. Recently, we focused our ongoing studies on a gorgonian coral identified as Junceella fragilis. From the results of our studies on this species, we report herein the isolation, structural determination, and bioactivity of two new briaranes, fragilides $P(\mathbf{1})$ and $Q(2)$, along with two known metabolites, robustolide F (3) [9,10] and juncin Z (4) [11] (Figure 1).
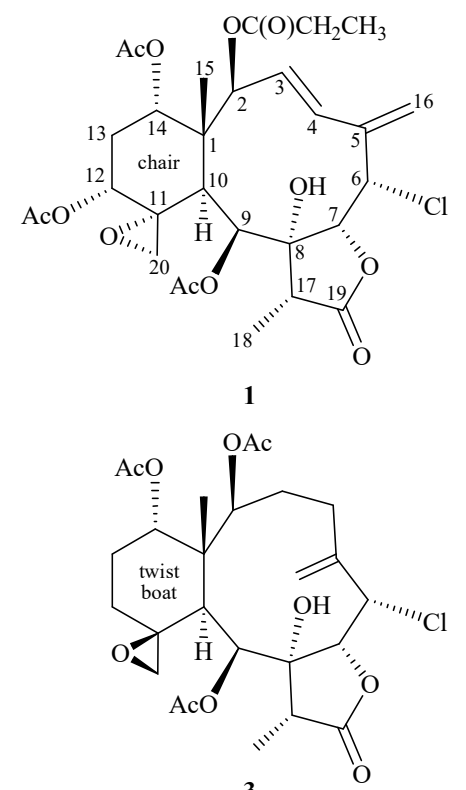

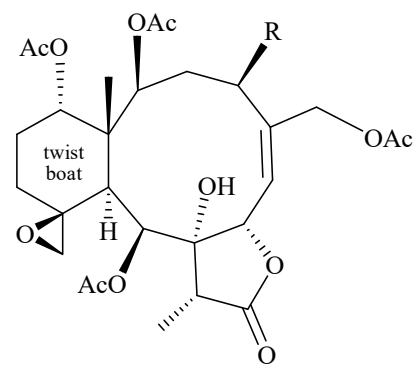

2: $\mathrm{R}=\mathrm{H}, \mathbf{5}: \mathrm{R}=\mathrm{OAc}$

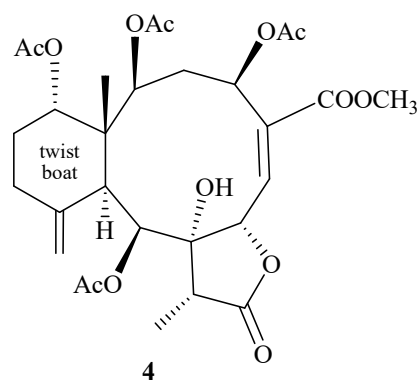

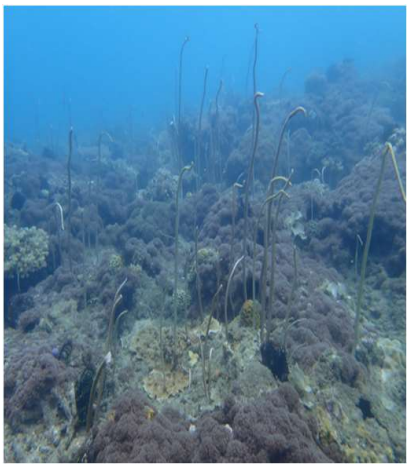

Junceella fragilis

Figure 1. Structures of fragilides $P(1), Q(2)$, juncins $Z(4), X(5)$, and robustolide $F(3)$ and a picture of Junceella fragilis.

\section{Results and Discussion}

Fragilide $\mathrm{P}(\mathbf{1})$ has the molecular formula $\mathrm{C}_{29} \mathrm{H}_{37} \mathrm{ClO}_{12}$ as deduced by (+)-ESIMS-which showed a pair of peaks at $m / z$ 635/637 (3:1) $\left[\mathrm{M}+\mathrm{H}^{+}\right]$, suggesting a chlorine atom in 1 -and further confirmed by (+)-HRESIMS at $m / z 635.18683$ (calcd. for $\mathrm{C}_{29} \mathrm{H}_{37}{ }^{35} \mathrm{ClO}_{12}+\mathrm{Na}, 635.18658$ ). The IR spectrum of 1 indicated the presence of hydroxy $\left(3466 \mathrm{~cm}^{-1}\right), \gamma$-lactone $\left(1783 \mathrm{~cm}^{-1}\right)$, and ester carbonyl $\left(1735 \mathrm{~cm}^{-1}\right)$ groups. The ${ }^{13} \mathrm{C}-\mathrm{NMR}$ spectral data (Table 1$)$ showed the presence of a disubstituted olefin $\left(\delta_{\mathrm{C}} 132.7\right.$, $\mathrm{CH}-4 ; 130.4, \mathrm{CH}-3)$ and an exomethylene $\left(\delta_{\mathrm{C}} 142.0, \mathrm{C}-5 ; 115.1, \mathrm{CH}_{2}-16\right)$. Moreover, five carbonyl resonances at $\delta_{\mathrm{C}} 174.6,173.3,170.3,169.9$, and 169.6 in the ${ }^{13} \mathrm{C}$ spectrum confirmed the presence of a $\gamma$-lactone and four other ester groups. In the ${ }^{1} \mathrm{H}$ NMR spectrum, three acetate methyls $\left(\delta_{\mathrm{H}} 2.11,2.09\right.$, 2.06 , each $3 \mathrm{H} \times \mathrm{s})$ and a propionate $\left(\delta_{\mathrm{H}} 2.31,2 \mathrm{H}, \mathrm{q}, J=7.6 \mathrm{~Hz} ; 1.11,3 \mathrm{H}, \mathrm{t}, J=7.6 \mathrm{~Hz}\right)$ were observed. An exocyclic epoxy group was elucidated from the signals of two oxygenated carbons at $\delta_{\mathrm{C}} 57.3$ (C-11) and $49.2\left(\mathrm{CH}_{2}-20\right)$. The proton chemical shifts at $\delta_{\mathrm{H}} 2.77(1 \mathrm{H}, \mathrm{dd}, J=3.2,1.2 \mathrm{~Hz}, \mathrm{H}-20 \mathrm{a})$ and $2.64(1 \mathrm{H}, \mathrm{d}$, $J=3.2 \mathrm{~Hz}, \mathrm{H}-20 \mathrm{~b}$ ) confirmed the presence of this group. Moreover, a methyl singlet, a methyl doublet, two aliphatic protons, a pair of aliphatic methylene protons, five oxymethine protons, a chlorinated methine proton, and a hydroxy proton were observed in the ${ }^{1} \mathrm{H}-\mathrm{NMR}$ spectrum of $\mathbf{1}$ (Table 1). 
Table $1 .{ }^{1} \mathrm{H}$ and ${ }^{13} \mathrm{C}-\mathrm{NMR}$ data for $\mathbf{1}$ and 2 .

\begin{tabular}{|c|c|c|c|c|}
\hline \multirow[b]{2}{*}{$\mathrm{C} / \mathrm{H}$} & \multicolumn{2}{|l|}{1} & \multicolumn{2}{|l|}{2} \\
\hline & $\delta_{H}{ }^{a}(J$ in $H z)$ & $\delta_{C},{ }^{b}$ Mult. & $\delta_{H}{ }^{c}(J$ in $\mathrm{Hz})$ & $\delta_{C},{ }^{d}$ Mult. \\
\hline 1 & & $49.2, \mathrm{C}$ & & $46.9, \mathrm{C}$ \\
\hline 2 & $5.73 \mathrm{~d}(9.6)$ & $75.6, \mathrm{CH}$ & $4.80 \mathrm{~d}(5.0)$ & $74.8, \mathrm{CH}$ \\
\hline 3 & $6.00 \mathrm{dd}(15.6,9.6)$ & $130.4, \mathrm{CH}$ & $2.44 \mathrm{~m} ; 1.68 \mathrm{~m}$ & 32.3, $\mathrm{CH}_{2}$ \\
\hline 4 & $6.89 \mathrm{~d}(15.6)$ & $132.7, \mathrm{CH}$ & $2.47 \mathrm{~m} ; 2.01 \mathrm{~m}$ & $24.9, \mathrm{CH}_{2}$ \\
\hline 5 & & $142.0, \mathrm{C}$ & & $139.8, \mathrm{C}$ \\
\hline 6 & $5.07 \mathrm{~d}(4.0)$ & $65.0, \mathrm{CH}$ & $5.53 \mathrm{~d}(10.5)$ & $119.2, \mathrm{CH}$ \\
\hline 7 & $4.16 \mathrm{~d}(4.0)$ & $80.6, \mathrm{CH}$ & $5.20 \mathrm{~d}(10.5)$ & $77.0, \mathrm{CH}$ \\
\hline 8 & & $82.8, \mathrm{C}$ & & $80.4, \mathrm{C}$ \\
\hline 9 & $5.19 \mathrm{~d}(2.0)$ & $72.2, \mathrm{CH}$ & $5.61 \mathrm{~d}(6.0)$ & $67.6, \mathrm{CH}$ \\
\hline 10 & 3.84 br s & $33.8, \mathrm{CH}$ & $2.29 \mathrm{~d}(6.0)$ & $39.6, \mathrm{CH}$ \\
\hline 11 & & $57.3, \mathrm{C}$ & & $62.4, \mathrm{C}$ \\
\hline 12 & $4.52 \mathrm{dd}(2.4,2.4)$ & $73.7, \mathrm{CH}$ & $2.28 \mathrm{~m} ; 1.16 \mathrm{~m}$ & 23.6, $\mathrm{CH}_{2}$ \\
\hline $13 \alpha / \beta$ & $2.32 \mathrm{~m} ; 2.06 \mathrm{~m}$ & 29.0, $\mathrm{CH}_{2}$ & $\begin{array}{c}1.77 \text { ddd }(15.5,10.0,10.0) ; \\
2.16 \mathrm{~m}\end{array}$ & $24.5, \mathrm{CH}_{2}$ \\
\hline 14 & $4.96 \mathrm{dd}(2.4,2.4)$ & $73.1, \mathrm{CH}$ & $4.90 \mathrm{~d}(5.0)$ & $72.9, \mathrm{CH}$ \\
\hline 15 & $1.18 \mathrm{~s}$ & $14.4, \mathrm{CH}_{3}$ & $1.01 \mathrm{~s}$ & $14.9, \mathrm{CH}_{3}$ \\
\hline $16 a / b$ & $5.34 \mathrm{~s} ; 5.26 \mathrm{~s}$ & $115.1, \mathrm{CH}_{2}$ & $\begin{array}{c}5.26 \mathrm{dd}(16.0,2.0) ; 4.23 \mathrm{~d} \\
(16.0)\end{array}$ & $67.1, \mathrm{CH}_{2}$ \\
\hline 17 & $2.84 \mathrm{q}(7.2)$ & $50.1, \mathrm{CH}$ & $2.34 \mathrm{q}(7.0)$ & $42.3, \mathrm{CH}$ \\
\hline 18 & $1.25 \mathrm{~d}(7.2)$ & $6.9, \mathrm{CH}_{3}$ & $1.16 \mathrm{~d}(7.0)$ & 6.7, $\mathrm{CH}_{3}$ \\
\hline 19 & & $174.6, \mathrm{C}$ & & $176.4, \mathrm{C}$ \\
\hline $20 a / b$ & $2.77 \mathrm{dd}(3.2,1.2) ; 2.64 \mathrm{~d}(3.2)$ & $49.2, \mathrm{CH}_{2}$ & $2.82 \mathrm{~d}(4.5) ; 3.23$ br d (4.5) & $59.0, \mathrm{CH}_{2}$ \\
\hline 2-OCOEt & $\begin{array}{l}2.31 \mathrm{q}(7.6) \\
1.11 \mathrm{t}(7.6)\end{array}$ & $\begin{array}{c}173.3, \mathrm{C} \\
27.7, \mathrm{CH}_{2} \\
8.8, \mathrm{CH}_{3}\end{array}$ & & \\
\hline $\begin{array}{l}\text { Acetate } \\
\text { methyls }\end{array}$ & $\begin{array}{l}2.11 \mathrm{~s} \\
2.09 \mathrm{~s} \\
2.06 \mathrm{~s}\end{array}$ & $\begin{array}{l}21.4, \mathrm{CH}_{3} \\
21.1, \mathrm{CH}_{3} \\
21.0, \mathrm{CH}_{3}\end{array}$ & $\begin{array}{l}2.22 \mathrm{~s} \\
2.14 \mathrm{~s} \\
2.04 \mathrm{~s} \\
2.01 \mathrm{~s}\end{array}$ & $\begin{array}{l}21.0, \mathrm{CH}_{3} \\
20.9, \mathrm{CH}_{3} \\
20.9, \mathrm{CH}_{3} \\
20.9, \mathrm{CH}_{3}\end{array}$ \\
\hline $\begin{array}{l}\text { Acetate } \\
\text { carbonyls }\end{array}$ & & $\begin{array}{l}170.3, \mathrm{C} \\
169.9, \mathrm{C} \\
169.6, \mathrm{C}\end{array}$ & & $\begin{array}{l}170.8, \mathrm{C} \\
170.8, \mathrm{C} \\
170.2, \mathrm{C} \\
169.5, \mathrm{C}\end{array}$ \\
\hline $8-\mathrm{OH}$ & $3.07 \mathrm{~s}$ & & $5.19 \mathrm{~s}$ & \\
\hline
\end{tabular}

${ }^{\text {a }}$ Spectra recorded at $400 \mathrm{MHz}$ in $\mathrm{CDCl}_{3}$ at $25^{\circ} \mathrm{C} .{ }^{\mathrm{b}}$ Spectra recorded at $100 \mathrm{MHz}$ in $\mathrm{CDCl}_{3}$ at $25{ }^{\circ} \mathrm{C}$. ${ }^{\mathrm{c}}$ Spectra recorded at $500 \mathrm{MHz}$ in $\mathrm{CDCl}_{3}$ at $25^{\circ} \mathrm{C}$. ${ }^{\mathrm{d}}$ Spectra recorded at $125 \mathrm{MHz}$ in $\mathrm{CDCl}_{3}$ at $25^{\circ} \mathrm{C}$.

Analyses of 2D-NMR (COSY and Heteronuclear Multiple Bond Correlation (HMBC)) data established a tetracyclic nucleus. This assignment was evident from the spin systems from $\mathrm{H}-2$ to H-3, H-3 to H-4, H-6 to H-7, H-9 to H-10, H-12 to $\mathrm{H}_{2}-13, \mathrm{H}_{2}-13$ to H-14, and $\mathrm{H}-17$ to $\mathrm{H}_{3}-18$ (Figure 2), while the HMBC between protons and quaternary carbons, such as $\mathrm{H}-2, \mathrm{H}-10, \mathrm{H}_{3}-15 / \mathrm{C}-1$; $\mathrm{H}-3, \mathrm{H}-6$, H-16b/C-5; H-6, H-9, H-10, H-17, H3-18, OH-8/C-8; H-9, H-10, H-20b/C-11; and H-17, $\mathrm{H}_{3}-18 / \mathrm{C}-19$ revealed the carbon skeleton (Figure 2). The epoxy group positioned at $\mathrm{C}-11 / 20$ was further confirmed by the HMBC between $\mathrm{H}-20 \mathrm{~b}$ to $\mathrm{C}-11$ and $\mathrm{C}-12$. The $\mathrm{C}-15$ methyl group was positioned at $\mathrm{C}-1$ from the $\mathrm{HMBC}$ between $\mathrm{H}_{3}-15$ to $\mathrm{C}-1$ and $\mathrm{C}-14$. The $\mathrm{HMBC}$ spectrum also revealed that the carbon signal at $\delta_{\mathrm{C}}$ 173.3 (C) was correlated with the signals of the methylene and methyl protons of propionate at $\delta_{\mathrm{H}} 2.31$ and 1.11, and it was assigned to the carbon atom of the propionate carbonyl group. The propionate at C-2 was confirmed from the connectivity between $\mathrm{H}-2$ and the carbonyl carbon of the propionate group. The HMBC revealed that an acetoxy group is attached to C-9. The hydroxy group at C-8 was deduced from the HMBC of a hydroxy proton $\left(\delta_{C} 3.07\right)$ to $C-7, C-8$, and C-9. Thus, the remaining acetoxy groups were positioned at C-12 and C-14 by analysis of the characteristic NMR signals $\left(\delta_{\mathrm{H}} 4.52\right.$, 
$\left.1 \mathrm{H}, \mathrm{dd}, J=2.4,2.4 \mathrm{~Hz} ; \delta_{\mathrm{C}} 73.7, \mathrm{CH}-12 ; \delta_{\mathrm{H}} 4.96,1 \mathrm{H}, \mathrm{dd}, J=2.4,2.4 \mathrm{~Hz} ; \delta_{\mathrm{C}} 73.1, \mathrm{CH}-14\right)$, although no HMBC was observed between $\mathrm{H}-12$ and $\mathrm{H}-14$ and the acetate carbonyl carbons.

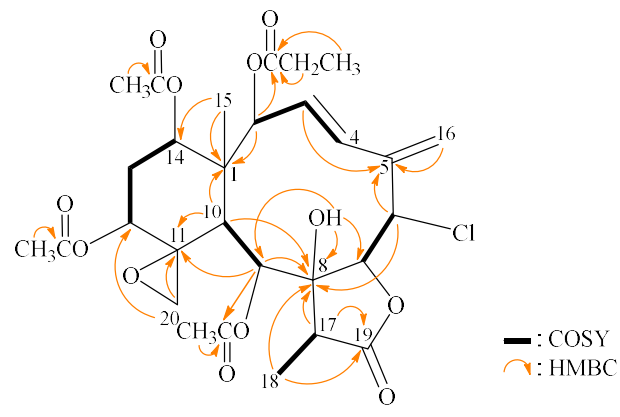

1

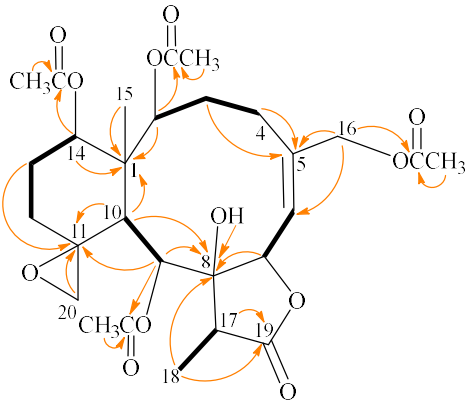

2

Figure 2. The COSY correlations and selective HMBC of $\mathbf{1}$ and 2.

According to a summary of the chemical shifts of 11,20-epoxy groups in briarane derivatives, with ${ }^{13} \mathrm{C}-\mathrm{NMR}$ data for C-11 and C-20 at $\delta_{\mathrm{C}} 55-61$ and $47-52 \mathrm{ppm}$, respectively, the epoxy group was $\alpha$-oriented and the cyclohexane ring existed in a chair conformation [12]; hence, the configuration of the 11,20-epoxy group in $\mathbf{1}\left(\delta_{\mathrm{C}} 57.3, \mathrm{C}-11 ; 49.2, \mathrm{CH}_{2}-20\right)$ should be $\alpha$-oriented, and the cyclohexane ring should be in a chair conformation. The $E$ configuration of the $\mathrm{C}-3 / 4$ double bond was determined from the large proton coupling constant $(J=15.6 \mathrm{~Hz})$ between $\mathrm{H}-3$ and $\mathrm{H}-4$. The stereochemistry of the 11 stereogenic centers of $\mathbf{1}$ was established by analysis of NOE correlations observed in a NOESY experiment and further supported by molecular mechanics 2 (MM2) force field analysis [13], as shown in Figure 3. In the NOESY spectrum, NOE correlations were observed between $\mathrm{H}-10$ and $\mathrm{H}-2 / \mathrm{H}-9 / \mathrm{OH}-8$, while no NOE correlation was seen with Me-15, suggesting that $\mathrm{H}-2, \mathrm{H}-9, \mathrm{H}-10$, and $\mathrm{OH}-8$ were all $\alpha$-oriented; meanwhile, a NOE correlation of Me- 15 with $\mathrm{H}-14$ indicated that $\mathrm{H}-14$ was $\beta$-oriented. In addition, $\mathrm{H}-12$ was found to correlate with $\mathrm{H}-13 \alpha / \beta$ and one proton of $\mathrm{C}-20$ methylene $\left(\delta_{\mathrm{H}} 2.77\right.$, $\mathrm{H}-20 \mathrm{a})$, indicating that the $\mathrm{C}-12$ acetoxy group was $\alpha$-oriented. $\mathrm{H}_{3}-18$ showed a NOE correlation with $\mathrm{OH}-8$, indicating that Me-18 was $\alpha$-oriented at C-17. H-7 exhibited NOE correlations with H-6 and $\mathrm{H}-17$, suggesting that $\mathrm{H}-6$ and $\mathrm{H}-7$ were positioned on the $\beta$ face. Furthermore, $\mathrm{H}-3$ showed a NOE correlation with $\mathrm{H}_{3}-15$; and $\mathrm{H}-4$ showed $\mathrm{NOE}$ correlations with $\mathrm{H}-2$ and $\mathrm{OH}-8$, demonstrating the $E$-configuration of $\Delta^{3}$ and establishing the s-cis diene moiety. As briaranes $\mathbf{1}$ and $\mathbf{2}$ were isolated along with a known metabolite 3 (robustolide F) from the same organism, and the absolute configuration of 3 was determined by single-crystal X-ray diffraction analysis [10], it is reasonable on biogenetic grounds and supported by the equal sign of optical rotation of $\mathbf{1}, \mathbf{2}$, and 3 to assume that $\mathbf{1}$ and $\mathbf{2}$ have the same absolute configurations as 3 . Therefore, based on the above findings, the configurations of the stereogenic carbons of 1 were determined as $1 R, 2 S, 6 S, 7 R, 8 R, 9 S, 10 S, 11 R, 12 R, 14 S$, and $17 R$ (see Figures S1-S10). It is interesting to note that the propionate group is rarely found in briarane-type natural products [12,14-18].

Fragilide Q (2) was found to have the molecular formula $\mathrm{C}_{28} \mathrm{H}_{38} \mathrm{O}_{12}$ as determined from its (+)-HRESIMS at $m / z 589.22562$ (calcd. for $\mathrm{C}_{28} \mathrm{H}_{38} \mathrm{O}_{12}+\mathrm{Na}$, 589.22555) $(\Omega=10)$. Its absorption peaks in the IR spectrum showed ester carbonyl, $\gamma$-lactone, and broad $\mathrm{OH}$ stretching at 1740, 1778, and $3273 \mathrm{~cm}^{-1}$, respectively. It was found that the ${ }^{1} \mathrm{H}$ and ${ }^{13} \mathrm{C}-\mathrm{NMR}$ spectra of 2 resembled those of a known analogue, juncin X (5) (Figure 1), isolated from gorgonian coral Junceella juncea collected off the South China Sea [11], except that the signals corresponding to the acetoxy group at C-4 in 5 were replaced by a proton in 2 . The locations of the functional groups were further confirmed by HMBC and COSY correlations (Figure 2); hence, fragilide $Q$ was assigned the structure of 2 , with the same stereochemistry as that of $\mathbf{1}$, and the configurations of the stereogenic carbons were elucidated as $1 S$, $2 S, 7 S, 8 R, 9 S, 10 S, 11 S, 14 S$, and 17R (Figure 3) (see Figures S11-S20). Due to the chemical shifts for 
C-11 and C-20 which appeared at $\delta_{C} 62.4$ and $59.0 \mathrm{ppm}$, respectively, the epoxy group was $\beta$-oriented and the cyclohexane ring should exist in a twisted boat conformation [12].

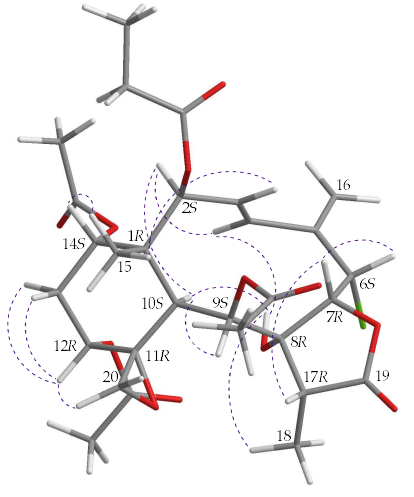

1

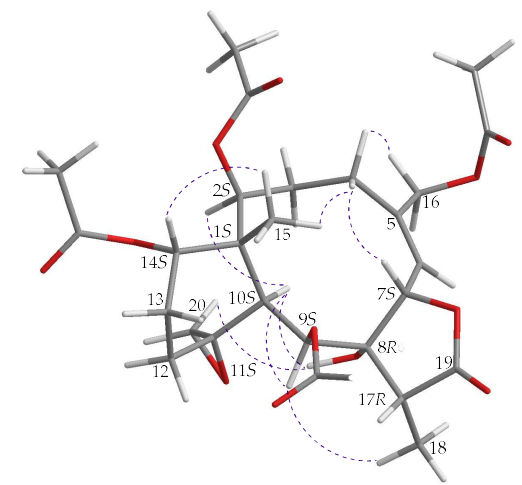

2

Figure 3. Selected protons with key NOESY $\left(i^{\prime}\right)$ correlations of $\mathbf{1}$ and $\mathbf{2}$.

Two known briaranes were isolated and identified as robustolide $F(3)[9,10]$ and juncin $Z$ (4) [11] by way of comparison with the spectroscopic and physical data reported in the literature.

In an in vitro anti-inflammatory activity assay, it was found that briarane 4 (juncin Z) showed a $25.56 \%$ inhibitory effect on the generation of superoxide anions by human neutrophils at a concentration of $10 \mu \mathrm{M}$, and briaranes $\mathbf{1}-\mathbf{3}$ were inactive.

\section{Materials and Methods}

\subsection{General Experimental Procedures}

The optical rotations were recored using a Jasco P-1010 digital polarimeter (Japan Spectroscopic, Tokyo, Japan). IR spectra were measured on a Thermo Scientific Nicolet iS5 FT-IR spectrophotometer (Waltham, MA, USA). NMR spectra were taken on a Jeol Resonance ECZ 400S (Tokyo, Japan) or on a Varian Inova (Palo, Alto, CA, USA) $500 \mathrm{NMR}$ spectrometer using the residual $\mathrm{CHCl}_{3}$ signal $\left(\delta_{\mathrm{H}} 7.26 \mathrm{ppm}\right)$ and $\mathrm{CDCl}_{3}\left(\delta_{\mathrm{C}} 77.1 \mathrm{ppm}\right)$ as the internal standard for ${ }^{1} \mathrm{H}$ and ${ }^{13} \mathrm{C}-\mathrm{NMR}$, respectively; coupling constants (J) are presented in Hz. Multiplicities of ${ }^{13} \mathrm{C}-\mathrm{NMR}$ data were determined by Distortionless Enhancement by Polarization Transfer (DEPT) experiments. ESIMS and HRESIMS mass spectra were measured on a Bruker mass spectrometer with 7 tesla magnets (model: SolariX FTMS system; Bruker, Bremen, Germany). HPLC separations were carried out on a Hitachi L-2130 pump (Tokyo, Japan) equipped with a Hitachi L-2455 photodiode array detector. The column used for HPLC was reversed-phase silica $(250 \mathrm{~mm} \times 21.2 \mathrm{~mm}, 5 \mu \mathrm{M}$, Luna RP-18e; Phenomenex Inc., Torrance, CA, USA). Column chromatography was carried out with Kieselgel 60 (230-400 mesh, Merck, Darmstadt, Germany). TLC was performed on precoated Kieselgel $60 \mathrm{~F}_{254}(0.25 \mathrm{~mm}$ thick, Merck), then sprayed with $10 \% \mathrm{H}_{2} \mathrm{SO}_{4}$ solution, followed by heating to visualize the spots.

\subsection{Animal Material}

The sea whip gorgonian coral Junceella fragilis was collected by hand in April 2017 using self-contained underwater breathing apparatus (SCUBA) gear at depths of 10-15 m off the coast of South Bay, Kenting, Taiwan. The samples were then stored in a $-20^{\circ} \mathrm{C}$ freezer until extraction. A voucher specimen was deposited in the National Museum of Marine Biology and Aquarium, Taiwan (NMMBA-TW-GC-2017-022). Identification of the species of this organism was performed by comparison as described in previous publications [3-5]. 


\subsection{Extraction and Isolation}

The freeze-dried and sliced bodies (wet/dry weight $=795 / 313 \mathrm{~g}$ ) of the coral specimen were prepared and extracted with a 1:1 mixture of $\mathrm{MeOH}$ and $\mathrm{CH}_{2} \mathrm{Cl}_{2}$ to give $19.0 \mathrm{~g}$ of crude extract which was partitioned between EtOAc and $\mathrm{H}_{2} \mathrm{O}$. The EtOAc extract $(8.0 \mathrm{~g})$ was applied on silica gel column chromatography (C.C.) and eluted with gradients of n-hexane/acetone (50:1 to 1:2, stepwise) to furnish eight fractions (fractions $A-H$ ). Fraction $G$ was chromatographed on silica gel C.C. and eluted with gradients of n-hexane/EtOAc (4:1 to 1:1, stepwise) to afford 16 subfractions (fractions G1-G16). Afterward, fraction G9 was separated by RP-HPLC using a mixture of $\mathrm{MeOH}$ and $\mathrm{H}_{2} \mathrm{O}$ (with volume/volume $=60: 40$; at a flow rate of $4.0 \mathrm{~mL} / \mathrm{min}$ ) to afford fragilide $\mathrm{P}(1,2.7 \mathrm{mg}$ ), fragilide $\mathrm{Q}$ $(2,1.8 \mathrm{mg})$, robustolide $\mathrm{F}(3,1.4 \mathrm{mg})$, and juncin $\mathrm{Z}(4,1.2 \mathrm{mg})$.

Fragilide P (1): amorphous powder; $[\alpha]_{\mathrm{D}}^{27}-14$ (c $\left.0.9, \mathrm{CHCl}_{3}\right)$; IR (ATR) $v_{\max } 3466,1783,1735 \mathrm{~cm}^{-1}$; ${ }^{1} \mathrm{H}$ and ${ }^{13} \mathrm{C}-\mathrm{NMR}$ data (see Table 1); ESIMS: m/z $635[\mathrm{M}+\mathrm{Na}]^{+}$; HRESIMS: m/z 635.18683 (calcd. for $\left.\mathrm{C}_{29} \mathrm{H}_{37}{ }^{35} \mathrm{ClO}_{12}+\mathrm{Na}, 635.18658\right)$.

Fragilide $\mathrm{Q}(2)$ : amorphous powder; $[\alpha]_{\mathrm{D}}^{28}-59\left(\right.$ c $\left.0.6, \mathrm{CHCl}_{3}\right)$; IR (ATR) $v_{\max } 3273,1778,1740 \mathrm{~cm}^{-1}$; ${ }^{1} \mathrm{H}$ and ${ }^{13} \mathrm{C}-\mathrm{NMR}$ data (see Table 1); ESIMS: $m / z 589[\mathrm{M}+\mathrm{Na}]^{+}$; HRESIMS: $m / z 589.22562$ (calcd. for $\left.\mathrm{C}_{28} \mathrm{H}_{38} \mathrm{O}_{12}+\mathrm{Na}, 589.22555\right)$.

Robustolide F (3): amorphous powder; $[\alpha]_{\mathrm{D}}^{23}-37\left(c 0.07, \mathrm{CHCl}_{3}\right)$ (ref. [9] $[\alpha]_{\mathrm{D}}^{26}-26.8(c) 1.038$, $\left.\left.\mathrm{CHCl}_{3}\right)\right)$; ref. [10] $\left.[\alpha]_{\mathrm{D}}^{25}-28\left(c 0.24, \mathrm{CHCl}_{3}\right)\right)$; IR (ATR) $v_{\max } 3288,1780,1735 \mathrm{~cm}^{-1} ;{ }^{1} \mathrm{H}$ and ${ }^{13} \mathrm{C}-\mathrm{NMR}$ data were found to be in absolute agreement with previous studies [9]; ESIMS: $m / z 565[\mathrm{M}+\mathrm{Na}]^{+}$.

Juncin Z (4): amorphous powder; $[\alpha]_{\mathrm{D}}^{23}+28\left(c\right.$ 0.06, $\left.\mathrm{CHCl}_{3}\right)$ (ref. [11] [ $\left.\alpha\right] \mathrm{D}+31.57\left(c\right.$ 0.95, $\left.\mathrm{CHCl}_{3}\right)$ ); IR (ATR) $v_{\max } 3433,1782,1738 \mathrm{~cm}^{-1} ;{ }^{1} \mathrm{H}$ and ${ }^{13} \mathrm{C}$-NMR data were found to be in absolute agreement with previous studies [11]; ESIMS: $m / z 617[\mathrm{M}+\mathrm{Na}]^{+}$.

\subsection{Molecular Mechanics Calculations}

The molecular models were generated by implementing the MM2 force field [13] in ChemBio 3D Ultra software (version 12.0) which was created by CambridgeSoft (PerkinElmer, Cambridge, MA, USA).

\subsection{Superoxide Anion Generation by Human Neutrophils}

Human neutrophils were obtained by means of dextran sedimentation and Ficoll centrifugation. Measurements of elastase release and superoxide anion generation were carried out according to previously described procedures [19]. Briefly, superoxide anion production was assayed by monitoring the superoxide-dismutase-inhibitable reduction of ferricytochrome c. Elastase release experiments were performed using MeO-Suc-Ala-Ala-Pro-Valp-nitroanilide as the elastase substrate.

\section{Conclusions}

The sea whip gorgonian coral Junceella fragilis, a zooxanthella-containing species [20], has been demonstrated to have a wide structural diversity of interesting marine-origin briarane-type diterpenoids [7], and the compounds of this type were suggested originally to be produced by the host corals and not by its zooxanthellae [21]. In our continued study of Junceella fragilis collected in the waters of Taiwan, two previously unreported briaranes, fragilides P (1) and Q (2), were isolated along with two previously described analogues, robustolide F (3) and juncin Z (4). The structures, including the absolute configurations of $\mathbf{1}$ and 2, were determined by using spectroscopic methods and comparing the spectroscopic and rotation values with those of a known related analogue, robustolide $F$ (3) $[9,10]$. Juncin Z (4) was found to display an inhibitory effect on the generation of superoxide anions by human neutrophils.

Supplementary Materials: The Supplementary Materials are available online. ESIMS, HRESIMS, IR, 1D $\left({ }^{1} \mathrm{H},{ }^{13} \mathrm{C}-\mathrm{NMR}\right.$, and DEPT spectra) and 2D (HSQC, COSY, HMBC, and NOESY) spectra of new compounds 1 and 2 and ESIMS, ${ }^{1} \mathrm{H},{ }^{13} \mathrm{C}-\mathrm{NMR}$, and DEPT spectra of 3 and 4. 
Author Contributions: C.-C.L., L.-C.H., T.-L.H. and P.-J.S. designed the whole experiment and contributed to manuscript preparation. J.-H.S., W.-F.C., Z.-H.W. and B.-R.P. analyzed the data.

Funding: This research was supported by grants from the National Museum of Marine Biology and Aquarium; the National Dong Hwa University; and the Ministry of Science and Technology, Taiwan (Grant Nos: MOST 104-2320-B-291-001-MY3 and 107-2320-B-291-001-MY3) awarded to Ping-Jyun Sung.

Conflicts of Interest: The authors declare no conflicts of interest.

\section{References}

1. Burks, J.E.; van der Helm, D.; Chang, C.Y.; Ciereszko, L.S. The crystal and molecular structure of briarein A, a diterpenoid from the gorgonian Briareum asbestinum. Acta Cryst. 1977, 33, 704-709. [CrossRef]

2. Samimi-Namin, K.; van Ofwegen, L.P. Overview of the genus Briareum (Cnidaria, Octocorallia, Briareidae) in the Indo-Pacific, with the description of a new species. ZooKeys 2016, 557, 1-44. [CrossRef] [PubMed]

3. Bayer, F.M. Key to the genera of octocorallia of Pennatulacea (Coelenterata: Anthozoa), with diagnoses of new taxa. Proc. Biol. Soc. Wash. 1981, 94, 902-947.

4. Bayer, F.M.; Grasshoff, M. The genus group taxa of the family Ellisellidae, with clarification of the genera established by J.E. Gary (Cnidaria: Octocorallia). Senckenberg. Biol. 1994, 74, 21-45.

5. Chen, C.-C.; Chang, K.-H. Gorgonacea (Coelenterata: Octocorallia) of Southern Taiwan. Bull. Inst. Zool. Acad. Sin. 1991, 30, 149-181.

6. Su, Y.-M.; Fan, T.-Y.; Sung, P.-J. 11,20-Epoxybriaranes from the gorgonian coral Ellisella robusta (Ellisellidae). Nat. Prod. Res. 2007, 21, 1085-1090. [CrossRef]

7. Chung, H.-M.; Wang, Y.-C.; Tseng, C.-C.; Chen, N.-F.; Wen, Z.-H.; Fang, L.-S.; Hwang, T.-L.; Wu, Y.-C.; Sung, P.-J. Natural product chemistry of gorgonian corals of genus Junceella-Part III. Mar. Drugs 2018, 16, 339. [CrossRef]

8. Su, Y.-D.; Su, J.-H.; Hwang, T.-L.; Wen, Z.-H.; Sheu, J.-H.; Wu, Y.-C.; Sung, P.-J. Briarane diterpenoids isolated from octocorals between 2014 and 2016. Mar. Drugs 2017, 15, 44. [CrossRef]

9. Tanaka, C.; Yamamoto, Y.; Otsuka, M.; Tanaka, J.; Ichiba, T.; Marriott, G.; Rachmat, R.; Higa, T. Briarane diterpenes from two species of octocorals, Ellisella sp. and Pteroeides sp. J. Nat. Prod. 2004, 67, 1368-1373. [CrossRef]

10. Sung, P.-J.; Chiang, M.Y.; Tsai, W.-T.; Su, J.-H.; Su, Y.-M.; Wu, Y.-C. Chlorinated briarane-type diterpenoids from the gorgonian coral Ellisella robusta (Ellisellidae). Tetrahedron 2007, 63, 12860-12865. [CrossRef]

11. Qi, S.-H.; Zhang, S.; Qian, P.-Y.; Xiao, Z.-H.; Li, M.-Y. Ten new antifouling briarane diterpenoids from the South China Sea gorgonian Junceella juncea. Tetrahedron 2006, 62, 9123-9130. [CrossRef]

12. Sheu, J.-H.; Chen, Y.-P.; Hwang, T.-L.; Chiang, M.Y.; Fang, L.-S.; Sung, P.-J. Junceellolides J-L, 11,20epoxybriaranes from the gorgonian coral Junceella fragilis. J. Nat. Prod. 2006, 69, 269-273. [CrossRef] [PubMed]

13. Allinger, N.L. Conformational analysis. 130. MM2. A hydrocarbon force field utilizing $V_{1}$ and $V_{2}$ torsional terms. J. Am. Chem. Soc. 1977, 99, 8127-8134. [CrossRef]

14. Guerriero, A.; D'Ambrosio, M.; Pietra, F. Bis-allylic reactivity of the funicolides, 5,8(17)-diunsaturated briarane diterpenes of the sea pen Funiculina quadrangularis from the Tuscan archipelago, leading to 16-nortaxane derivatives. Helv. Chim. Acta 1995, 78, 1465-1478. [CrossRef]

15. Chiasera, G.; Guerriero, A.; D'Ambrosio, M.; Pietra, F. On the funicolides, briaranes of the Pennatulacean coral Funiculina quadrangularis from the Tuscan archipelago: Conformational preferences in this class of diterpenes. Helv. Chim. Acta 1995, 78, 1479-1489. [CrossRef]

16. Sheu, J.-H.; Sung, P.-J.; Su, J.-H.; Wang, G.-H.; Duh, C.-Y.; Shen, Y.-C.; Chiang, M.Y.; Chen, I.-T. Excavatolides $\mathrm{U}-\mathrm{Z}$, new briarane diterpenes from the gorgonian Briareum excavatum. J. Nat. Prod. 1999, 62, 1415-1420. [CrossRef]

17. Sung, P.-J.; Chen, Y.-P.; Su, Y.-M.; Hwang, T.-L.; Hu, W.-P.; Fan, T.-Y.; Wang, W.-H. Fragilide B: A novel briarane-type diterpenoid with a s-cis diene moiety. Bull. Chem. Soc. Jpn. 2007, 80, 1205-1207. [CrossRef]

18. Cheng, W.; Ji, M.; Li, X.; Ren, J.; Yin, F.; van Ofwegen, L.; Yu, S.; Chen, X.; Lin, W. Fragilolides $\mathrm{A}-\mathrm{Q}$, norditerpenoid and briarane diterpenoids from the gorgonian coral Junceella fragilis. Tetrahedron 2017, 73, 2518-2528. [CrossRef] 
19. Yu, H.-P.; Hsieh, P.-W.; Chang, Y.-J.; Chung, P.-J.; Kuo, L.-M.; Hwang, T.-L. 2-(2-Fluorobenzamido) benzoate ethyl ester (EFB-1) inhibits superoxide production by human neutrophils and attenuates hemorrhagic shock-induced organ dysfunction in rats. Free Radic. Biol. Med. 2011, 50, 1737-1748. [CrossRef]

20. Walker, T.A.; Bull, G.D. A newly discovered method of reproduction in gorgonian coral. Mar. Ecol. Prog. Ser. 1983, 12, 137-143. [CrossRef]

21. Kokke, W.C.M.C.; Epstein, S.; Look, S.A.; Rau, G.H.; Fenical, W.; Djerassi, C. On the origin of terpenes in symbiotic associations between marine invertebrates and algae (zooxanthellae). J. Biol. Chem. 1984, 259, 8168-8173. [PubMed]

Sample Availability: Samples of the compounds 1-4 are not available from the authors.

(C) 2019 by the authors. Licensee MDPI, Basel, Switzerland. This article is an open access article distributed under the terms and conditions of the Creative Commons Attribution (CC BY) license (http://creativecommons.org/licenses/by/4.0/). 